\title{
A educação como prática da liberdade por meio do Teatro do Oprimido: novas aplicações educacionais
}

\author{
Education as a practice of freedom through the Theater \\ of the Oppressed: new educational applications
}

La educación como práctica de libertad por

medio del Teatro del Oprimido: nuevas

aplicaciones educacionales

MÁDSON FRANCISCO DA SILVA (Da

MARIA DE FÁtIMA GOMES DA SILVA (Db

\section{Resumo}

$\mathrm{O}$ artigo em questão resulta de uma pesquisa de mestrado intitulada "O Teatro do Oprimido e o Enfrentamento à Violência Escolar", que teve como objetivo principal pesquisar a problemática da violência escolar no âmbito das práticas pedagógicas de professoras dos anos finais do ensino fundamental. Com relação à metodologia, optouse pela abordagem qualitativa de pesquisa, com ênfase na pesquisa-ação. Os dados foram coletados por meio de oficinas do Teatro do Oprimido (TO), com base nas ideias de Augusto Boal $(2015,2013)$, o que implicou novas práticas de ensino e de aprendizagem nas escolas investigadas. Complementarmente, também foram realizadas observações participantes e questionários. Para a análise dos dados, recorreu-se à análise de conteúdo temático categorial. Os resultados indicaram que as oficinas do TO possibilitaram às docentes participantes desta investigação novas formas de enfrentamento da violência escolar, com a participação dos estudantes, mediante uma educação como prática da liberdade. Concluiu-se, portanto, que este estudo serviu para despertar a consciência emancipadora das professoras e dos(as) estudantes, por meio das práticas vivenciadas nas escolas investigadas, e que o Teatro

\footnotetext{
a Universidade de Pernambuco (UPE), Nazaré da Mata, PE, Brasil. Mestre em Educação, e-mail: mamadson123@hotmail.com

b Universidade de Pernambuco (UPE), Nazaré da Mata, PE, Brasil. Doutora em Ciências da Educação, e-mail: fatimamaria18@gmail.com
} 
do Oprimido constitui um excelente recurso de enfrentamento à violência escolar e de valorização dos diversos saberes vividos e reinventados na vitalidade dos/as estudantes e de toda a comunidade escolar para se libertarem da opressão e se reencontrarem com sua essência humanizada, libertadora e emancipada nas lutas diárias. Fortaleceu-se, neste estudo, a relevância de uma educação como prática da liberdade.

Palavras-chave: Educação. Liberdade. Teatro do Oprimido.

\begin{abstract}
The article in question results from a master's research entitled "the Theater of the Oppressed and Confronting School Violence", whose main objective was to research the issue of school violence within the ambit of practices pedagogical activities of teachers in the final years of elementary regarding the methodology, a qualitative research approach was chosen, with an emphasis on action research. Data were collected through workshops at Theater of the Oppressed (TO), based on ideas of Augusto Boal (2015, 2013), which implied new teaching and learning practices in the investigated schools. In addition, participant observations and questionnaires were also carried out. For data analysis, categorical thematic content analysis was used. The results indicated that the TO workshops enabled teachers participating in this investigation, new ways of coping with school violence, with the participation of students, through education as practice of freedom. It was concluded, therefore, that this study served to awaken the emancipatory awareness of teachers and students, through the practices experienced in the investigated schools, and that the Theater of the Oppressed is an excellent resource for coping with school violence and for valuing the diverse knowledge experienced and reinvented in the vitality of students and the entire school community to free themselves from oppression and to rediscover their humanized, liberating and emancipated essence in daily struggles. In this study, the relevance of education as a practice of freedom.
\end{abstract}

Keywords: Education. Freedom. Theater of the Oppressed.

\title{
Resumen
}

El artículo resulta de una investigación de maestría titulada "El teatro del oprimido y el enfrentamiento de la violencia escolar", que tuvo como objetivo principal investigar la problemática de la violencia escolar en ambientes de prácticas pedagógicas de profesoras de años finales de escuela primaria. Se eligió el enfoque cualitativo de investigación con énfasis en la investigación-acción como metodología. Los datos fueran recogidos en talleres de Teatro del Oprimido (TO), basados en ideas de Augusto Boal (2015, 2013), regenerando nuevas prácticas de enseñanza y aprendizaje en las escuelas investigadas. También se realizaron observaciones participantes $y$ cuestionarios. Se buscó un análisis de los datos en contenido temático categórico. Los resultados indicaran que los talleres de TO posibilitaron a los docentes participantes de esa investigación nuevas maneras de enfrentamiento de la violencia escolar, con la participación de estudiantes. Se concluye que la investigación sirvió para el despertar una consciencia emancipadora de las profesoras y estudiantes participantes y que el Teatro del Oprimido constituye un recurso de enfrentamiento a la violencia escolar y 
de valoración de los distintos saberes vividos y reinventados en la vitalidad de los estudiantes y de toda comunidad escolar para que se liberten de las opresiones y se reencuentren con su esencia humanitaria, libertadora y emancipada en las luchas diarias. Se fortaleció, en esa investigación, la relevancia de una educación como práctica de la libertad.

Palabras clave: Educación. Libertad. Teatro del Oprimido.

\section{Introdução}

Falar de educação na contemporaneidade como prática da liberdade é inerentemente desafiante ao se olhar os contextos que envolvem as escolas. Não é necessário passar muito tempo em uma unidade escolar para se registrar alguma manifestação opressiva, seja na forma física, seja na oral, seja na comportamental, seja na estrutural, seja na política da unidade educativa ou do território em que ela está inserida. A violência/opressão rodeia nossas vivências escolares, pessoais e sociais. A partir disso, questiona-se: como é que os atores sociais da escola contemporânea percebem as dimensões opressivas dentro e fora da escola? Como e a partir de que se pode afirmar que a educação promove a prática da liberdade?

Essas questões serão respondidas ao longo dos itens deste estudo. Eles apresentarão registros de oficinas do Teatro do Oprimido - TO no âmbito de duas escolas municipais, resultado de uma pesquisa de mestrado que teve como problema a seguinte indagação: é possível minimizar a violência escolar, por meio do Teatro do Oprimido, na perspectiva de uma vivência da educação como prática da liberdade?

O texto faz uma inferência nas afirmativas dos sujeitos da pesquisa. Estes afirmam que, apesar dos problemas e das limitações ocasionadas pela violência escolar, tida como opressão, a educação é, sim, uma prática da liberdade, porque permite a efetivação da transformação pessoal por meio da conscientização e da mudança de comportamento a partir das realidades de vida de cada um.

Este estudo foi metodologicamente estruturado na pesquisa qualitativa com ênfase na pesquisa-ação. Contou com a observação participante e o questionário como instrumento complementar de investigação, uma vez que o Teatro do 
Oprimido (TO) foi instrumentalizado como forma de viabilizar a compreensão da violência a partir das próprias vivências escolares e pessoais no campo empírico.

As discussões estão assentes teoricamente em Freire (2016, 2014a, 2014b, 2009), Braga (2015), Mafra (2008) e Santiago (2006), entre outros referenciais que discutem a violência escolar e a educação como prática da liberdade. Como resultado principal, registra-se a concepção dos estudantes e das professoras acerca da educação e a leitura de mundo deles, expostas em oficinas do Teatro do Oprimido. O TO é uma forma de teatro semelhante às outras, porém, diferencia-se por ser realizada com os oprimidos e para que eles se libertem de toda opressão, aliando-se e construindo uma educação libertadora, humanizante e emancipatória para um mundo melhor onde cada pessoa possa Ser Mais.

\section{Metodologia}

Para o desenvolvimento da pesquisa que resultou neste artigo, elegeu-se a pesquisa qualitativa, por considerar que essa dimensão investigativa inaugura uma compreensão sobre a realidade das pessoas e dos fatores à sua volta. Assim, consideramos entre suas variações que "as observações qualitativas são registradas e interpretadas, e algumas vezes codificadas minuciosamente" (STAKE, 2013, p. 22), o que nos permite verificar elementos que estão subjacentes à natureza do objeto e das pessoas investigadas. Nesse sentido, no âmbito desta investigação, procurou-se saber quais são os fatores determinantes que contribuem para as práticas da violência escolar e como o Teatro do Oprimido pode ser um recurso pedagógico de diálogo no combate a todo tipo de opressão/violência dentro e fora da escola, com fins de reafirmar a educação como prática da liberdade, da emancipação e da humanização.

Além dessa abordagem de pesquisa, também se optou pela pesquisa-ação neste estudo, por entender que esse procedimento metodológico proporcionaria caminhos que permitiriam estabelecer vivências integradas entre quem investiga e os atores sociais em um profundo diálogo sobre a violência escolar, sobretudo, porque não se pode defender a educação como prática da liberdade sem se ter um 
pertencimento a ela, estar no meio e com ela (vivência). Nessa perspectiva, Thiollent e Colette (2013, p. 7) consideram:

A pesquisa-ação é instrumento de diálogo e de construção de novas práticas acadêmicas, de práticas que pressupõem a concepção de universidade como espaço social, voltado à construção de conhecimentos que possam alavancar transformações em prol da sociedade como um todo, quer no campo social, ambiental, econômico, tecnológico, científico, educacional e cultural.

Desse modo, Thiollent e Colette referem-se à necessidade de aproximar a universidade ao seu campo empírico de investigação, proporcionando uma interação entre pesquisador, sujeitos, objeto e outros elementos ligados à pesquisa. Nesse sentido, ressalta a importância de traçar vivências significativas no âmbito da pesquisa. No que toca à coleta de dados, esta aconteceu por meio de oficinas realizadas com base na metodologia do Teatro do Oprimido (TO), da observação participante - que foi fundamental para o discernimento de comentários - , e de situações mencionadas no âmbito das oficinas do TO e do questionário.

O Teatro do Oprimido foi utilizado como um recurso para a coleta de dados neste artigo, já que na sua linguagem se apresentam possibilidades de entendimento, reflexões e intervenção sobre a violência escolar. Assim, o TO foi utilizado sob a forma de oficinas, que foram realizadas com vinte estudantes e cinco professoras de duas escolas municipais. Inicialmente, foram propostas oito oficinas do TO, que foram orientadas pelo livro Jogos para atores e não atores (BOAL, 2015).

Nesse viés, em diálogo com o pensamento freiriano, as oficinas emergiram de discursos a respeito das práticas educativas, das práticas violentas dentro e fora da escola e de todo sentimento de opressão que existe nos sujeitos envolvidos, considerando os medos e as violências ocorridas dentro e fora da escola, já que o que acontece fora infere profundamente na vida dos estudantes e nas relações escolares. Sendo assim, abaixo será possível entender como se caracterizou cada oficina do Teatro do Oprimido, as quais foram embasadas no pensamento de Paulo Freire e interpretadas a partir das opressões relatadas.

$1^{a}$ Oficina de TO: Na primeira oficina, foram coletadas as ideias iniciais dos estudantes sobre Teatro do Oprimido, bem como sobre os conceitos de oprimido e opressor. Depois disso, toda a concepção montada por Boal $(2013,2015)$ acerca da 
temática foi apresentada, a fim de que os estudantes conhecessem e refletissem sobre o conceito do TO.

$2^{a}$ Oficina: Nesse segundo momento, foi desenvolvida a primeira categoria do arsenal do Teatro do Oprimido, que é "Sentir tudo o que se toca" (BOAL, 2015, p. 99), com o intuito de fazer com que cada estudante pudesse utilizar seu corpo para sentir as emoções e tudo que está na situação ou no ambiente que permite que ele possa tocar ou ser tocado. Sendo assim, buscou-se, através dessa oficina, discutir acerca de toda violência física que acontece no espaço escolar, questionando sobre as tipologias da violência escolar sem aprofundar discussões. A maioria dos participantes citou a violência física, a verbal, o bullying e a violência contra o patrimônio como sendo as principais formas de opressão no ambiente escolar.

- Para tanto, foi eleito o jogo chamado de "O Círculo de Nós" (BOAL, 2015, p. 105), no qual os participantes pegam um na mão do outro em um grande círculo, afastam-se, misturam-se no menor espaço possível e, depois, tentam encontrar as mesmas mãos que estavam segurando no início.

$3^{\mathrm{a}}, 4^{\mathrm{a}}$ e $5^{\mathrm{a}}$ Oficinas: Nessas oficinas, trabalhamos com três categorias do Teatro do Oprimido: a segunda categoria - "escutar tudo o que se ouve"-; a terceira categoria - "Ativando os vários sentidos"-; e a quarta categoria- "Ver tudo que se olha". A segunda categoria, "escutar tudo o que se ouve” (BOAL, 2015, p. 129), teve o intuito de desenvolver nos alunos a atenção para escutar as vozes dos opressores e dos oprimidos, os sons da sua natureza humana e toda voz ressoante do centro da violência escolar, que nem sempre está tão clara, mas que sempre está lá, de uma forma ou de outra, clamando por liberdade e aceitação. Nessas Oficinas, também foi desenvolvida a terceira categoria, "Ativando os vários sentidos" (BOAL, 2015, p. 129), a fim de que os participantes desenvolvessem, além do sentir e do escutar, a visão que corresponde e se interliga à quarta categoria, que é "Ver tudo que se olha" (BOAL, 2015, p.164). Buscou-se, então, perceber de uma maneira mais ampla e profunda as práticas de violência escolar, no tocante à violência verbal, emocional, visual e física, que interferem no seu posicionamento na escola e no mundo enquanto sujeitos fazedores de sua história.

Nessas oficinas, foram utilizados os seguintes jogos: 
- “Ninguém com ninguém” (BOAL, 2015, p. 115), que é um jogo em que são formadas algumas duplas, mas um participante sobra e ministra alguns comandos, orientando os outros membros a movimentarem-se. O participante que não está em uma dupla fala, por exemplo, mão com mão, pé na perna, cabeça nas costas e, assim, os demais fazem o que é orientado. Quando se grita a frase-chave "ninguém com ninguém", os participantes se misturam e outro membro sobra. Assim, é trabalhado o enfrentamento à inibição, bem como o desenvolvimento dos sentidos físicos e auditivos. Nessa oportunidade, os estudantes falaram dos sentimentos de abandono e solidão presentes, sobretudo, no âmago familiar.

- Já “A espada de pau parisiense” (BOAL, 2015, p. 118) é um jogo em que os participantes ficam em círculos e um no centro. Este último usa uma espada imaginária, com a qual dispara ataques contra os membros que estão no círculo e eles imaginam que estão sendo atacados. Sendo um jogo de movimentos, gritos e imaginação, os participantes foram levados a pensar sobre os golpes da opressão manifestados no transcorrer da história, que nem sempre marcaram fisicamente, mas deixaram marcas enraizadas nas emoções, na sexualidade e na dignidade de cada um.

- O "Hipnotismo colombiano" (BOAL, 2015, p. 101) é um jogo em que cada participante fica de frente para o seu par e o hipnotiza, trocando de condição depois. Nesse jogo, os participantes partilharam da alienação e coerção violenta vinda dos opressores, que os obrigavam a ficarem submetidos a condições que eles não gostariam de estar, como o silêncio diante de atos errôneos por medo de represálias, a obrigatoriedade de ter que dar algo ou pagar para entrar num lugar público ou, ainda, ter que fazer atividades não relacionadas à liberdade de escolha.

$6^{a}$ Oficina: Aplicação da quinta categoria, intitulada "A memória dos sentidos". Nela, vê-se uma dimensão que nos ajuda a interligar "a memória, a emoção e a imaginação" para preparar uma apresentação ou associar algo já 
vivenciado ao tempo real em que o sujeito está vivendo (BOAL, 2015, p. 211). Nessa oficina, são utilizadas as memórias dos estudantes sobre as opressões que eles vivenciaram ou vivenciam nos âmbitos familiar, social ou escolar. Para tanto, eles assumem uma posição de agressor ou agredido no espaço escolar, ou que esteja prejudicando a sua estima enquanto um ser reflexivo e interventor da realidade. Nessa oficina, houve muitas manifestações emotivas e transformadoras acerca do que os sujeitos sentiam e são na escola e no mundo.

- Nessa oficina, os jogos teatrais do oprimido voltaram-se para a realidade de cada sujeito participante. De início, foi proclamada a música "Aquarela", de Toquinho. $\mathrm{Na}$ sequência, os estudantes manifestaram, em desenho, suas lembranças sobre o que se lembravam da letra da música. Essa experiência foi uma reativação da memória e uma abertura da consciência para as lembranças violentas nos meios escolar, familiar e social.

$7^{\mathrm{a}}$ e $8^{\mathrm{a}}$ Oficina: Com o fim das categorias do arsenal do TO e com algumas pequenas inferências nos jogos sobre os opressores e oprimidos na perspectiva da violência escolar, os estudantes e as professoras, que são sujeitos desta pesquisa, junto ao pesquisador, fizeram dessas oficinas um espaço mais profundo e pertinente de reflexão a respeito do objeto teórico e empírico desta investigação, através de representações de fatos violentos presentes no ambiente educativo que oprimem cada um deles ou que são opressões similares advindas da violência, as quais limitam as práticas pedagógicas no seu fomento ao processo de ensino-aprendizagem e a formação humana dos pares. Sendo assim, essas representações da violência foram refletidas à luz do pensamento sensível e simbólico que, segundo Boal (2009), ocupa uma reflexão natural ou objetiva sobre as pessoas e os fatores. Espontaneamente, nessas oficinas, estávamos observando toda a natureza do objeto investigado através da arte fomentada pelo arsenal do Teatro do Oprimido. Além disso, foi proporcionado um momento de diálogo em que cada um falou de seus medos, de suas limitações, de seus sentimentos e de condições que nos envolvem profundamente numa dimensão opressora e livre, em que todos, desde os estudantes, passando pelos pesquisadores ao secretário de educação, tiveram a oportunidade de sentir, pensar, agir, chorar e também sorrir. 
O segundo instrumento da coleta de dados foi a observação participante, uma vez que esta permite a inserção do investigador no locus pesquisado com um maior atentamento ao discurso e à prática de quem e do que está sendo investigado. A respeito desse tipo de instrumento, Lüdke e André (1986, p. 26) afirmam que "a observação é o principal instrumento da investigação. O observador pode recorrer aos conhecimentos e experiências pessoais como auxiliares no processo de compreensão e interpretação do fenômeno observado". Em outras palavras, o pesquisador tem nesse instrumento a oportunidade de ver as situações e as condições naturais do campo investigativo, podendo, então, discernir tais fatores a partir do seu próprio conhecimento. Neste estudo, a observação participante caracteriza-se como um instrumento de aproximação física, enquanto também permitiu a inferência sobre os fatos vividos e narrados no centro e nos entornos da pesquisa.

A propósito do questionário, podemos considerar que, no âmbito da investigação, esse instrumento foi um mecanismo de interligação entre os dados escritos e os discutidos no contexto das oficinas do TO. As falas das professoras e das estudantes aqui analisadas foram extraídas do questionário e tiveram "por objetivo o conhecimento de opiniões, crenças, sentimentos, interesses, expectativas, situações vivenciadas etc.” (GIL, 1999, p. 128), sobretudo para resgatar essas quatro últimas dimensões e com mais rigor a última, já que as oficinas com os jogos do TO sempre estiveram voltadas para a interpretação das vivências de cada sujeito em contexto de opressão — violência. Para a análise dos dados, recorreu-se à análise de conteúdo temático categorial (BARDIN, 2014).

\section{A relação opressor-oprimido dentro e fora da escola}

Neste subitem, abordaremos a problemática da relação opressor-oprimido dentro e fora da escola. Nessa perspectiva, estamos considerando a violência escolar como opressão vivenciada por estudantes, professores e funcionários das unidades de ensino. Por outro lado, destacamos que, em meio à relação opressor-oprimido, os oprimidos podem se libertar através da consciência crítica e reflexiva, a qual, 
naturalmente, os conduz a uma ação de rebeldia que provoca um retorno à sua primeira vocação humanizada de Ser Mais. Assim, na medida em que o ser humano se compreende inconcluso e por se completar, dialoga com os outros e se opõe a práticas de seus opressores, que somente se libertam por meio da intervenção consciente dos seus oprimidos (FREIRE, 2014b).

Sobre a relação opressor-oprimido, na perspectiva da violência escolar, recorremos ao que relata a estudante 1 (2017), quando menciona:

Violência escolar é uma coisa muito comum. Pode acontecer em qualquer escola, pode acontecer com qualquer aluno/a. Mas, é mais comum com pessoas com algum tipo de doença, mas que o opressor não quer nem saber porque já deve ter acontecido algum tipo de violência com ele em casa, na rua e até mesmo na escola.

Observa-se que ela fala da violência como uma ação natural dentro da comunidade escolar e confirma a vulnerabilidade para a opressão a que todos estão sujeitos. No entanto, a estudante menciona que, embora a violência possa acontecer com todos, ela é mais provável de ocorrer com pessoas que têm alguma patologia ou fragilidade/limitação, motivo injustificável para o opressor agredir e se ausentar da sua culpa. Porém, ressaltamos que ele provavelmente também já foi oprimido em outras situações, até mesmo no lugar onde deveria ser mais amado, a própria casa.

Assim como no caso das escolas de Goiânia-GO, de Realengo-RJ, dos EUA e de tantas outras, podemos afirmar que, infelizmente, com muita facilidade, é possível ver na internet, nos jornais, na TV, nos rádios e em outros meios de comunicação notícias sobre violência nas escolas. Essa violência é fruto de uma sociedade que marginaliza e exclui a juventude, bem como é "incapaz" de oferecer dignidade e de garantir direitos, deveres e, até mesmo, empregos a todos esses jovens.

A respeito da marginalidade, Freire (2016, p. 124) considera "que ela implica fome, doenças, raquitismo, dor, deficiência mental, morte, crime, promiscuidade, desesperação, impossibilidade de ser”, uma vez que sua ação efetiva a negação do Ser Mais. Ainda reitera que, se ela "não é uma opção, o homem marginalizado tem sido excluído do sistema social e é tido fora dele, quer dizer, é um objeto de violência" (FREIRE, 2016, p. 125), sofrendo as consequências da negação que se 
inicia na miséria e se completa na experiência da morte por fome, suicídio ou assassinato.

O que pesa de forma eminente no fomento à violência escolar que oprime alunos, professores e outros membros da comunidade educativa é a marginalização crescente na sociedade, principalmente em comunidades mais carentes e distantes do acesso a educação de qualidade, cultura, esportes, lazer e saúde. Naturalmente, fazemos questão de reafirmar neste texto que ser pobre ou não ter um médio ou grande poder aquisitivo não faz de uma pessoa um ser violento, um marginal. Existem muitas pessoas nas periferias que trabalham, estudam, respeitam as diferenças e lutam por direitos, igualdade e paz. São verdadeiros cidadãos que, mesmo não descobertos ou não tendo status social, são exemplos para os que estão em volta. Por outro lado, ao olharmos para outras pessoas mais carentes no coração da sociedade, percebemos o quanto seus sonhos e objetivos têm se perdido pelo caminho, pelo fato de terem poucos recursos e de serem pouco acreditadas por outros.

Qualquer pessoa que chegue hoje na escola pública brasileira, sobretudo nas escolas municipais, poderá ver o seguinte cenário de relações entre opressores e oprimidos: conflitos entre alunos sem um motivo formal, justificados apenas por um olhar; brigas motivadas por namorados(as) ou paqueras que, muitas vezes, já têm compromissos com outras pessoas; discussões exageradas baseadas em ofensas, reivindicando espaço onde desejam sentar ou apenas deixar sua mochila enquanto passeiam pela escola ou pelas ruas no horário de aula; ofensas contra professores, colegas, pais e outros funcionários por motivos diversos, como, por exemplo, resultado de rendimento escolar e merenda; humilhação de membros da escola por causa de sua orientação sexual, opção religiosa e raça; intensificação do bullying por conta de características físicas e cognitivas e por questões que envolvem os familiares; violação e degradação do patrimônio público; controle na entrada e saída da escola, em que alguns estudantes cobram de outros taxas ou lanches para permitir o acesso à unidade escolar; exposição de materiais que podem machucar o outro; utilização de títulos da marginalidade para tentar ou até mesmo conseguir oprimir professores e alunos da unidade escolar. São inúmeras as práticas e as 
características dessa relação opressor-oprimido que podem ser visualizadas a partir de um olhar inerente para a escola.

Nesse sentido, Silva e Mendonça (2015), ao se referirem aos estudantes que costumam adotar essas tais práticas, destacam:

Assim, há estudantes que sofrem com a violência do ambiente escolar, e estes podem ser vítimas diretas, ou expectadores, testemunhas. E há aquele "aluno agressor" que dissemina a violência no ambiente escolar, que por suas ações descaracterizam o papel inicial da escola, que seria o da educação, que não reconhece mais a autoridade docente, já que age em sua presença, dentro da sala de aula, sem qualquer respeito à sua figura e, por fim, inviabiliza o direito de todos a uma escola segura. E esse aluno juntamente com o agressor externo (que muitas vezes se confundem) são responsáveis pelo sentimento de insegurança na escola (SILVA; MENDONÇA, 2015 p. 45).

Assim sendo, as relações de opressão acima referidas caracterizam as práticas da violência escolar e demonstram o quanto é firme o domínio de quem as pratica, inviabilizando até mesmo a autoridade docente no seu fazer pedagógico e desestruturando o espaço escolar como um ambiente seguro e de aprendizagem. Silva e Mendonça (2015) ainda evidenciam a presença de um opressor externo que também atua por meio das práticas dos opressores que estão na escola. Eles agem mediante uma orientação que instiga os sujeitos ao sentimento de superioridade e autoritarismo, como se a escola, especificamente a sala de aula, fosse uma pertença exclusiva do opressor, entendendo que sua função é transmitir saberes necessários às práticas violentas e não à liberdade.

Nessa perspectiva, as práticas de violência escolar, por mais desumanizadas que sejam, não podem consolidar a desumanização do homem e da mulher no espaço educativo, mesmo que elas apareçam nesse momento como algo firmado. Historicamente, porém, elas podem ser mudadas pela educação problematizadora em função da liberdade do homem e da mulher. Assim sendo, a crítica à opressão presente na vida das pessoas não pode deixar de estar na proposta educacional libertadora (WEFFORT, 2014), uma vez que, conscientes ou não, sempre estamos em condições de opressão. A educação precisa ser e estar nesse movimento de construção de saberes e identidades, de luta pela liberdade, de reformulação do pensamento, da interligação entre o eu e o outro, numa relação inconclusa, mas que sempre está se completando.

A esse respeito, Freire (2000, p. 119-120) enfatiza: 


\begin{abstract}
Inacabado como todo ser vivo - a inconclusão faz parte da experiência vital - o ser humano se tornou, contudo, capaz de reconhecer-se como tal. A consciência do inacabamento 0 insere num permanente movimento de busca a que se junta, necessariamente, a capacidade de intervenção no mundo, mero suporte para os outros animais. Só o ser inacabado, mas que chega a saber-se inacabado, faz a história em que socialmente se faz e se refaz. O ser inacabado, porém, que não se sabe assim, que apenas contacta o seu suporte, tem história, mas não a faz. O ser humano que, fazendo a história, nela se faz, conta não só a sua, mas também a dos que apenas a têm.
\end{abstract}

Fazendo uma analogia dessa afirmação de Freire, compreendemos que ele se refere à nossa capacidade de entender a nossa inconclusão, visto que esse inacabamento nos conscientiza para a intervenção na realidade, no contexto e na história que estamos fazendo individual e coletivamente. Nesse propósito, o ato de fazer história também nos habilita a refazê-la e contá-la como um testemunho verídico da emancipação que alcançamos por meio da humanização e da superação da relação opressor-oprimido.

$\mathrm{Na}$ conclusão da abordagem sobre a relação opressor-oprimido dentro e fora da escola, revigoramos o retorno à humanização do homem e da mulher viabilizado pelo amor que os liberta. A relação opressor-oprimido é desumanizante, mas o coração e a consciência de quem está nessa relação podem ser humanizados, percebendo que não somente vive, mas é capaz de compreender e dar sentido à experiência vital e histórica que possui. Superando a opressão, os sujeitos podem, juntos, modificar a história, reduzir o que os esmaga, encontrar a herança do Ser Mais caracterizada pela beleza e pelo prazer de viver como alguém que sempre se supera e, assim, compreende sua inconclusão.

\title{
Consequências da violência escolar e o exercício de práticas educativas problematizadoras
}

A violência escolar, em todas as suas formas, prejudica as práticas educativas e é fruto de opressões experimentadas na convivência familiar, na degradação da autoestima do sujeito e, naturalmente, na gritante violência social que reflete profundamente na escola. As consequências da violência escolar são caracterizadas pelo medo de aprender e ensinar, pelos alunos que deixam de estudar, pelos 
docentes que desistem da profissão e adoecem no exercício dela, pelo tempo perdido em conflitos que tomam o tempo pedagógico e dicotomizam a escola, a qual luta por unidade e por outros variados fatores. Todavia, é preciso voltar os olhares para as práticas educativas — neste momento, não como ações oprimidas, mas como ações problematizadoras que conduzem os estudantes à reflexão, à crítica e à intervenção sobre si e sobre o mundo, pois se espera que práticas educativas problematizadoras despertem os professores e os estudantes para um ato de rebeldia, de oposição à opressão, caracterizada, nesse caso, pela violência escolar. Nesse sentido, Freire (2000, p. 81) explicita:

\begin{abstract}
Uma das questões centrais com que temos que lidar é a promoção de posturas rebeldes em posturas revolucionárias que nos engajam no processo radical de transformação do mundo. A rebeldia é ponto de partida indispensável, é deflagração da justa ira, mas não é suficiente. A rebeldia enquanto denúncia precisa de se alongar até uma posição mais radical e crítica, a revolucionária, fundamentalmente anunciadora. A mudança do mundo implica a dialetização entre a denúncia da situação desumanizante e o anúncio de sua superação, no fundo, o nosso sonho.
\end{abstract}

Desse modo, as práticas educativas precisam problematizar a violência escolar por meio de um ato de oposição a ela, constituindo-se como uma postura rebelde na efetivação de um mundo em transformação. Essa ação faz com que os estudantes se encontrem em uma situação em que a revolução se trata de sua liberdade, de seu direito de aprender, de anunciar, de se superar e de realizar seus sonhos, contribuindo para que outros também se libertem, sonhem e se realizem, sem medo da marginalização que oprime e busca se oficializar na escola. Em suma, o que propõe Paulo Freire é uma pedagogia que permita na experiência do Ser Mais uma integração com "os sujeitos da educação como seres históricos, situados, de relação, críticos, criativos e curiosos cujos conteúdos da educação emergem da realidade política e social” (SANTIAGO, 2006, p. 76).

Nessa perspectiva, a liberdade não acontece antes da humanização e esta também é motivada e estruturada no cerne da prática pedagógica. Por essa razão, reiteramos com Braga (2015, p. 49, grifos nossos):

A humanização ganha vida em ações humanizadoras. Objetivá-la é transpor da condição de substantivo - humanização - para o estado de verbo - humanizar. Essa perspectiva remonta à dimensão antropológica da humanização. Relações rígidas contribuem para introjeção da autoridade exacerbada, cujo reflexo na vida profissional se faz sentir no ser humano pelo medo de exercer sua autenticidade, mesmo em 
relações que considerem seu esforço e intenção de conhecer a realidade como conteúdo, possibilidades de acesso a níveis de autonomias mais elevados. Nas perspectivas espacial e temporal, ser humano é agir humanamente. Humanizar-se ao humanizar as relações vivenciadas na prática pedagógica docente-discente e as ações se demonstram como meios provocativos à ação humanizadora.

Fazendo uma analogia do pensamento de Braga (2015), podemos afirmar que a humanização é um processo da ação do homem e da mulher, que a compreendem e se humanizam na sua experiência de vida. Cabe ressaltar que a ação pedagógica, quando atribuída apenas ao rigor, fechado ao diálogo e à amorosidade, bloqueia a construção de saberes que estruturam os estudantes numa transcendência da humanização. A prática pedagógica problematizadora é uma vivência relacional dos pares escolares, porque propicia a interligação entre corpo docente e discente, para, assim, amadurecerem juntos, no conhecimento humanizado e emancipador que aqui remonta à ideia do conhecimento a partir da história e das condições do sujeito.

Nessa perspectiva, a vivência do diálogo entre as pessoas permite uma relação humanizada entre todos os sujeitos capazes de vivenciar uma educação problematizadora que enfrenta a opressão e a violência escolar. A humanização nas práticas educativas problematizadoras é também uma ação autêntica dos sujeitos que manifestam suas subjetividades e caminham na diversidade, sem reduzir a forma autêntica imbricada na vitalidade dos outros.

Nesse sentido, apesar das consequências da violência no ambiente educativo, "a escola não pode ser local de legitimação da marginalidade, mas de sua superação" (RODRIGUES, 2003, p. 55), ou seja, precisa ser um espaço onde a violência se encerra com a interação respeitosa de seus indivíduos e com as contribuições integradas à formação humana do coletivo. A função da educação problematizadora é também fomentar a valorização humana por meio do respeito aos saberes e às experiências de vida, desenvolvendo e efetivando a diversidade cultural, religiosa, sexual, étnica e tantas outras que fazem do mundo um lugar diverso, mais belo, com uma única identidade aos seus, que é a de ser humano, a de Ser Mais.

A fundamentação da educação problematizadora que enfatizamos neste texto “está fundamentada sobre a criatividade e estimula uma ação de reflexão verdadeira sobre a realidade, respondendo, assim, à vocação dos homens que não são seres autênticos senão quando se comprometem na procura e na transformação criadora" 
(FREIRE, 2016, p. 132). Desse modo, a criatividade é uma resposta de uma reflexão legítima da realidade em que os homens e as mulheres se autenticam num fazer transformador por meio da educação e no mundo.

\section{A educação como prática da liberdade nas concepções das professoras nas oficinas do teatro do oprimido}

A propósito da liberdade, Mafra (2008, p. 289) assegura que o poder condiciona a existência da liberdade, "Porém, no contexto da modernidade, a liberdade é a capacidade de mobilidade dentro da sociedade de normalização (da intimidade, da sexualidade, da saúde, da estética, etecetera)". Trata-se, então, da busca do poder que cada indivíduo deseja ter para expressar sua identidade e sua subjetividade humana no meio em que vive. Nesse mesmo sentido, refletindo sobre as categorias poder e liberdade a partir das dimensões de Foucault e Freire, Mafra (2008) entende que, numa perspectiva ideológica, é preciso reorganizar a utopia para pensar as questões do poder e da liberdade nas ações contemporâneas de luta. Em conformidade com essa primeira dimensão, reorganização da utopia, surge o nível simbólico de promover, em nosso entendimento, a revolução nos conflitos por meio e com todas as pessoas subordinadas a algum tipo de opressão "(analfabetos, negros, índios, sem-teto, sem terras, homossexuais, favelados etc.), na restauração da alteridade e dignidade humana para fazer um planeta com mais justiça, paz e harmonia ecossocial entre os seres vivos e, por que não, os não vivos” (MAFRA, 2008, p. 291).

Em busca da liberdade viabilizada pelas práticas educativas e que estão no meio da opressão, é "preciso ressaltar que as práticas educativas acontecem tentando superar todas as adversidades" (PROFESSORA 4, 2017). Nesse caso, a adversidade é a violência contra as pessoas, os objetos e o lugar. Nessa configuração, "atividades que façam os estudantes expressarem seus sentimentos (poesias, redações, pinturas, desenhos, teatro)" são essenciais para estimular o protagonismo deles no reencontro promovido pelo processo de ensino-aprendizagem, enfrentando a violência (PROFESSORA 2, 2017). 
A propósito da função da prática pedagógica no meio das interfaces da violência, em que se encontram as relações opressor-oprimido, outra docente ressalta:

\begin{abstract}
A prática pedagógica tenta abranger o opressor e o oprimido, uma vez que 0 opressor também está inserido no processo de ensino. O professor como educador, muitas vezes, tenta reverter os casos que são possíveis. Orienta, corrige e por fim acredita na mudança de comportamento dos mesmos. A função da prática pedagógica é formar adultos conscientes, que exerçam o bem. Os indivíduos envolvidos na violência necessitam de uma atenção redobrada com o intuito de desconstruir suas ações (PROFESSORA 1, 2017, grifo nosso).
\end{abstract}

O comentário da professora acima reitera uma dimensão global da prática pedagógica compreendida por ela e pelas colegas de profissão no cerne da opressão. Refere-se ao lugar de onde os educadores, de forma autêntica, procuram transformar as vivências. Assim, "quanto mais tolerantes, quanto mais transparentes, quanto mais críticos, quanto mais curiosos e humildes, tanto mais assumem autenticamente a prática docente” (FREIRE, 2009, p. 81). Essa posse da docência não se reduz ao conhecimento curricular, mas se desdobra nas realidades desafiadoras que precisam ser encaradas no chão da escola em enfrentamento à opressão. Nesse sentido, o princípio de liberdade emergente da ação educativa ocorre quando esta afirma que tanto o opressor quanto o oprimido são abraçados pelo ato transformador de educar, que se caracteriza pela orientação, correção e credibilidade na capacidade de todos se transformarem em cidadãos passíveis de exercer o bem, a cidadania.

Afirmando que a prática educativa é libertadora, a professora 4 (2017) infere que a ação educativa direciona o caminho do conhecimento e forma o(a) educando(a) como um(a) sujeito(a) autônomo(a), tornando-se "crítico, autoconfiante, determinado e que não se deixa enganar. E que, acima de tudo, sabe fazer escolhas conscientes". Isso significa compreender o mundo no qual está inserido a partir da consciência que "é gerada na prática social de que se participa" (FREIRE, 1990, p. 29), superando a ingenuidade de uma cultura do assim mesmo que inaugura o conformismo e a aceitação do ser menos (FREIRE, 2014b, 2011). Desse modo, identificamos nessa afirmação a categoria da emancipação por meio da educação, que oferta sua parcela de conhecimento para a formação de sujeitos que 
dialogam com o científico, com o que está na profundidade e nos entornos de sua experiência vital.

A educação bancária, ingênua e coercitiva não considera o conhecimento dos educandos, executa-se sem refletir, sem problematizar, afugentando-se da indagação, e é rigorosamente manipuladora. Ao tratar da educação bancária, Paulo Freire (2014b, p. 81) destaca que, “'na visão 'bancária' da educação, o 'saber' é uma doação dos que se julgam sábios aos que julgam nada saber". Além disso, acrescenta: “O educador, que aliena a ignorância, se mantém em posições fixas, invariáveis. Será sempre o que sabe, enquanto que os educandos serão sempre os que não sabem" (FREIRE, 2014b, p.81). Essa educação opressora nega conhecimentos culturais, sociais e pessoais herdados e formados por cada estudante, fechando a possibilidade de um ensino dialógico e transformador, em que "o ato de ensinar, vivido pelo professor ou professora, vai desdobrando-se, da parte dos educandos, no ato de estes conhecerem o ensinado" (FREIRE, 2009, p. 81).

Por outro lado, a educação problematizadora pressupõe a autonomia do sujeito em sua liberdade construída na sua historicidade, conhecendo, reconhecendo e transformando seu mundo a partir de sua criatividade. Nessa perspectiva, a professora menciona:

A educação deve encontrar caminhos que permitam a libertação do indivíduo,
possibilitando que o mesmo tenha condições de descobrir-se e apoderar-se como
sujeito de sua própria história. A liberdade acontece através de uma educação
emancipadora, e é necessário que haja uma dialogicidade e interligação entre o
educador e o educando para se ter um conhecimento participativo e transformador
(PROFESSORA 3, 2017).

Com um posicionamento evidente sobre quais caminhos deve seguir a educação, essa professora resgata questões que envolvem o empoderamento do indivíduo sobre sua própria história, não como um objeto, mas como alguém que é responsável por si. A ideia de que a liberdade é fruto de uma educação emancipadora cabe, nesse posicionamento, à legitimidade de uma educação que não fica na "ideia", mas parte da conscientização dos homens e das mulheres para sua prática participativa e emancipadora.

A esse respeito, a professora 2 (2017) considera: 
A educação é um dos instrumentos mais eficientes para a promoção da liberdade, pois pode formar indivíduos críticos e livres. A prática educativa pressupõe a transmissão de saberes entre sujeitos. Nesse sentido, envolve elementos sociais e políticos. $\mathrm{O}$ sujeito que aprende constrói sua própria história e intervém na sociedade baseada em princípios éticos. Entendemos a liberdade proveniente das práticas educativas quando 0 indivíduo compreende seu papel enquanto sujeito transformador, crítico e autônomo. Liberdade, nesse sentido, implica também responsabilidade e consequência de seus atos (PROFESSORA 2, 2017).

No trecho acima, a docente concebe a educação como um meio legítimo de alcançar a liberdade na formação das pessoas. Ao utilizar o termo "transmissão", não desejou aludir à educação bancária, a qual se deposita o conhecimento, mas quis dizer que a prática educativa norteia e alimenta o conhecimento entre as pessoas, abrangendo as variadas situações e condições como elemento social e político. Por fim, sua contribuição ainda evidencia que o processo de aprendizagem que envolve o sujeito faz com que ele construa sua história e realize intervenções na sociedade, partindo da ética. Em conformidade com essas inferências, a professora ainda reitera que a liberdade gera responsabilidade e consequências acerca da ação do homem e da mulher no mundo. Logo, práticas educativas humanizadas e problematizadoras formam cidadãos capazes de se emancipar e transformar o lugar onde se vivencia a realidade.

\section{A educação como possibilidade à liberdade: as concepções dos estudantes}

Depois de ter verificado a ótica das professoras da investigação sobre a educação como possibilidade à liberdade, conforme vimos anteriormente, voltamos aos estudantes com os seguintes questionamentos: Você compreende a educação como possibilidade à liberdade? A que liberdade a educação o leva ou levará?

No primeiro momento, um profundo e temporário silêncio se estabeleceu no meio da oficina, pois as palavras EDUCAÇÃO e LIBERDADE se apresentavam interligadas, uma como fruto da outra. No entanto, até chegarmos neste ponto, fomos evidenciando as formas das opressões vivenciadas por cada um ou coletivamente, sem tocar na educação como prática da liberdade. Naquele momento, individualmente, cada um precisou manifestar sua opinião a partir de sua 
consciência, sem ser coagido pela ideia do outro, entendendo que falamos tanto de opressão, opressor e oprimido para que, enfim, chegássemos à liberdade, pelo menos numa perspectiva epistemológica.

Rompendo o silêncio estabelecido nos precedentes da oficina com os questionamentos, os estudantes da investigação começaram a pontuar, de forma geral, o que seria essa liberdade emanada da educação. Para uns, a liberdade seria a conclusão do ensino básico. Para outros, a ideia de liberdade ainda precisa ser mais reverberada no campo educativo.

Em intersecção, a estudante 20 (2017) considera que a educação como estrutura libertária "abre portas para o mundo, para se ter um futuro melhor", ressaltando que a qualificação e a benevolência do futuro dependem muito do que se é construído na educação básica. Nesse aspecto, o estudante 18 (2017) compreende a educação como uma oportunidade de "conhecer coisas novas que me ajudará no futuro a ter um trabalho, fazer uma faculdade, me qualificar mais". A respeito dessa última colocação, o estudante comenta que esses resultados serão para todos que seguirem a proposta educacional/pedagógica. Nessa perspectiva, elucida-se o status desses estudantes dentro de uma trama social em transformação, visto que eles terão um futuro melhor, viajarão, terão uma formação e um trabalho como fruto de sua prática educacional no ensino básico. Freire (2001, p. 36) acredita que "a prática educacional não é o único caminho à transformação social necessária à conquista dos direitos humanos, contudo [...], sem ela, jamais haverá transformação social. A educação consegue dar às pessoas maior clareza para lerem o mundo", de modo que essa clareza é um caminho visivelmente dependente de uma práxis transformadora, que é de responsabilidade dos sujeitos históricos por meio da educação.

Conforme mencionado na metodologia, as oficinas do Teatro do Oprimido aconteceram nas escolas da investigação, na Secretaria Municipal de Educação de Nazaré e no Campus Mata Norte da Universidade de Pernambuco (UPE). Nessas mobilidades da coleta de dados, os estudantes (re)conheceram espaços esquecidos ou não conhecidos como a UPE e tiveram a oportunidade de conhecer outras pessoas, outros espaços e outras linguagens, escapando um pouco daquele lugar já conhecido como sua escola de origem. Nessa perspectiva, compreendendo também 
o TO como educativo, a estudante 16 (2017) discorre que a educação como possibilidade à liberdade promove uma transportação a "novos lugares e pessoas".

Com o alinhamento dessas lembranças somadas a outras experiências de superação por meio da educação, todos os participantes compreenderam que a liberdade promovida pela educação se dá no campo do conhecimento, das relações e da exploração e redescoberta do espaço, como também na conquista de elementos como formação em nível básico, superior e profissional. Em suma, todos voltaram para casa com um novo olhar para a escola e sua oferta educacional, acreditando e sonhando com uma liberdade distante, porém, almejada e realizável.

\section{Os estudantes como sujeitos da própria aprendizagem: vivências, realidades e formas de enxergar e ler o mundo}

$\mathrm{Na}$ oficina que subsidiou este item, estávamos tratando das notícias sobre a violência escolar e dramatizando outras situações opressivas dentro das escolas investigadas. Nesse sentido, buscamos verificar a opinião dos estudantes sobre suas próprias formas de enxergar e ler o mundo, partindo de suas vivências e realidades. Subjacentes às emoções das notícias e aos comentários acima referidos, os estudantes perceberam as situações de opressão relacionadas aos riscos de marginalização e miséria e ao abandono familiar, político e social a que, muitas vezes, estão subordinados. Sendo assim, os estudantes presentes na oficina, em unanimidade, disseram que o mundo é um lugar violento, injusto e até "horrível" para evidenciar a crueldade presente nas vivências.

A estudante 15 (2017) ainda reiterou que “o mundo é um pouco injusto com pessoas que têm uma opção sexual diferente ou alguma doença, ou porque é negro", ressaltando algumas especificidades de opressão. Por outro lado, apesar da violência gerada por alguns estudantes das escolas investigadas, todo o corpo docente, gestão e demais membros institucionais consideram TODOS os estudantes como sujeitos da própria aprendizagem.

A professora 2 (2017) descreve: 
O estudante sujeito de sua própria aprendizagem é protagonista na construção dos saberes e não é um ser sem respostas. E que é importante que sua realidade e sua forma de estudar também sejam consideradas pelo educador. O educando se posiciona de forma crítica, ele se reconhece como um ser político. E o conhecimento é baseado nas suas experiências diárias (conhecimentos prévios).

Inicialmente, a docente acima já configura uma posição ativa dos estudantes no firmamento de seus saberes e reacende a perspectiva de que o educador deve acolher a forma como eles estudam. Complementando que os estudantes são responsáveis por sua aprendizagem, a referência delineia as experiências de vida como base inicial do conhecimento dos discentes que são críticos e políticos. Pertencente à mesma escola, a professora 1 (2017) afirma:

Os estudantes, diante das suas realidades, enxergam o mundo como um lugar de "possibilidades", onde todos podem e conseguem se tornar o que querem. Buscam aprimorar suas habilidades priorizando suas raízes. Enxergam-se como seres capazes de transformar a sociedade que vivem exercendo seu papel no mundo.

Nesse sentido, partindo de forma específica para suas vivências e realidades, constatamos em observações e relatos que os estudantes, em sua maioria, estão sempre em contato com diversas atividades na escola, a saber: construção de mapas, desenhos, atividades manuais relacionadas a corte e pintura dentro e fora das disciplinas, participam de partidas de futebol durante, antes e depois dos jogos interclasses e das bandas (fanfarras) das escolas onde estudam e até de outras, bem como procuram ou são motivados a participar/contribuir com outras atividades no campo educativo.

Quando alguns estudantes saem da escola, surge a responsabilidade de trabalhar para contribuir com o sustento familiar. Esse cenário independe se esse sujeito é mais velho, do meio ou mais novo, de modo que o compromisso de todos é de alguma forma prover alimentos e recursos para que a família fique mais confortável. Entre algumas atividades para a aquisição de recursos estão: vender frutas e verduras na feira ou porta a porta, carregar frete (transportar as mercadorias dos feirantes e clientes), realizar faxinas em casas, lojas e em outros espaços, vender trufas, empadas ou picolés, fazer manutenção de carros em oficinas formais ou limpezas simples em frente de casa. 
Boa parte dos estudantes também frequenta atividades religiosas. Em suas igrejas, participam de coral, de grupo de estudo bíblico e/ou de doutrina (catequese, escola dominical, reunião, grupos de oração, entre outros) e de ministérios relacionados à música e ao teatro (jogral).

No meio cultural, outros estudantes também se inserem nas atividades artísticas da cidade. A esse respeito, uma participante comenta:

Os estudantes têm uma forma positiva de enxergar o mundo. Seja aprendendo a lidar com a realidade que o pertence (rodeia) e dela extraindo o seu melhor e transformando em arte, cultura, aprendizado. Ou muitas vezes dando continuidade a todo um legado cultural que seus antepassados com esforço insistem em deixar (PROFESSORA 4, 2017).

A menção acima infere sobre a positividade dos estudantes a partir de sua colaboração com o meio cultural. A cidade da pesquisa, Nazaré da Mata - PE, é a capital estadual do Maracatu. Nela, existem muitos grupos que há décadas, século, preservam a identidade do maracatu rural, que é passada de geração em geração. Nessa continuidade da educação cultural do maracatu estão alguns sujeitos da pesquisa que tocam, dançam e cantam nessas manifestações culturais, assim como no coco de roda, na ciranda, nas quadrilhas e em outras atividades artísticas que se manifestam na cidade ao longo do ano.

Portanto, revigora-se a certeza de que a educação é, sim, libertadora e que a preservação de aspectos culturais e religiosos, entre outros, e do compromisso com a família por meio do trabalho é uma dimensão que contempla a diversidade do mundo e a capacidade do homem e da mulher de se inserir, lutar, contribuir, transformar e manter viva a ação humanizante que se traduz no fazer e no Ser Mais das pessoas. A educação escolar é, nesse enredo, um cenário principal de onde partem as primeiras e principais inspirações acertadas e conscientes para uma vida toda, que precisa ser em vários olhares lida e experimentada no mais elevado grau de aprendizagem, libertação e emancipação. 


\section{Considerações finais}

Alguns dos principais desafios da educação na atualidade emergem da violência escolar. Nesse cenário, discutir sobre a educação como prática da liberdade é um ato desafiante, porque ela se confronta com as relações opressivas dentro da comunidade escolar e busca preservar a essência educativa como possibilidade de transformação pessoal e social dos sujeitos que constituem a unidade educacional.

No entanto, as experiências deste estudo com a instrumentalização do Teatro do Oprimido demonstram o quanto a escola é um espaço de manifestação de conflitos vindos de fora, mas que, precedente a isso, é um território de conhecimento, de partilhas, de construção de identidades e, sobretudo, de humanização, libertação e emancipação.

Os itens que antecederam a conclusão deste artigo apresentam a concepção de professoras e estudantes de escolas públicas municipais, que, apesar dos desafios insistentes que tecem a problemática da violência escolar, afirmam que a educação é libertadora porque permite uma nova leitura de mundo e, consequentemente, uma nova inserção do sujeito que atua, transforma e supera as manifestações opressivas conforme sua inquietação e busca por completar-se na efetivação do Ser Mais.

Nesse sentido, a prática da liberdade por meio da educação ocorrerá inicialmente nas criativas possibilidades de mudanças e se efetivará com a concretude da situação superada, transformada e adequada à realidade de cada pessoa dentro de sua identidade, dignidade e inserção no mundo como sujeito que se engaja na escola, na família, no mercado de trabalho, nos campos culturais e religiosos.

Por fim, é preciso que fique evidente na conclusão deste estudo que a vivência do Teatro do Oprimido permitiu registrar que a construção da educação libertadora somente é possível através de uma comunidade escolar que seja dialógica, amorosa, comprometida com a política educacional e com a ascensão humana, que é capaz de dirimir situações opressivas do campo escolar até o cerne violento da comunidade social e familiar. Assim, reitera-se que a prática educativa libertadora é capaz de dar frutos e já tem dado muitos quando nela se nutre o amor à vida, nunca a morte, nunca o preconceito, nunca a violência. 
Conclui-se, portanto, que este estudo serviu para despertar a consciência emancipadora das professoras e dos/as estudantes, por meio das práticas vivenciadas nas escolas investigadas, e para evidenciar que o Teatro do Oprimido constitui um excelente recurso de enfrentamento à violência escolar e de valorização dos diversos saberes vividos e reinventados na vitalidade dos/as estudantes e de toda a comunidade escolar para se libertarem da opressão e se reencontrarem com sua essência humanizada, libertadora e emancipada nas lutas diárias. Isso posto, fortaleceu-se, neste estudo, a relevância de uma educação como prática da liberdade.

\section{Referências}

BARDIN, L. Análise de conteúdo. Lisboa: Edições 70, 2014.

BOAL, A. Jogos para atores e não atores: Augusto Boal. São Paulo: Cosac Naify, 2015.

BOAL, A. Teatro do Oprimido e outras poéticas políticas: Augusto Boal. São Paulo: Cosac Naify, 2013.

BOAL, A. A estética do oprimido. Rio de Janeiro: Garamond, 2009.

BRAGA, M. M. Prática pedagógica docente-discente: traços da pedagogia de Paulo Freire na sala de aula. Recife: Editora da UFPE, 2015.

FREIRE, P. Conscientização. Trad. Tiago José Risi Leme. São Paulo: Cortez, 2016.

FREIRE, P. Educação como prática da liberdade. 36. ed. rev. e atual. São Paulo: Paz e Terra, 2014 a.

FREIRE, P. Pedagogia do Oprimido. 56. ed. rev. e atual. Rio de Janeiro: Paz e Terra, 2014b.

FREIRE, P. Pedagogia da Esperança: um reencontro com a pedagogia do oprimido. 16. ed. Rio de Janeiro: Paz e Terra, 2009.

FREIRE, P. Pedagogia dos sonhos possiveis. São Paulo: Editora da UNESP, 2001.

FREIRE, P. Pedagogia da Indignação: cartas pedagógicas e outros escritos. São Paulo: Editora da UNESP, 2000.

FREIRE, P. Alfabetização: leitura da palavra e do mundo. Trad. Lólio Lourenço de Oliveira. Rio de Janeiro: Paz e Terra, 1990.

GIL, A. Métodos e técnicas de pesquisa social. 5. ed. São Paulo: Atlas, 1999.

LUDKE, M.; ANDRÉ, M. Pesquisa em educação: abordagem qualitativa. São Paulo: EPU, 1986.

MAFRA, J. A conectividade do presente com a história em Freire e Foucault. In: GODOTTI, M. et al. (Comp.). Paulo Freire: Contribuciones para la pedagogía. Buenos Aires: 
CLACSO, enero 2008. Disponível em: http://biblioteca.clacso.edu.ar/clacso/formacionvirtual/20100720033957/24Mafra.pdf. Acesso em: 20 mar. 2018.

RODRIGUES, N. Por uma nova escola: o transitório e o permanente na educação. 13. ed. São Paulo: Cortez, 2003.

SANTIAGO, E. Formação, currículo e prática pedagógica em Paulo Freire. In: BATISTA NETO, J.; SANTIAGO, M. E. (Org.). Formação de professores e prática pedagógica. Recife: Fundação Joaquim Nabuco: Massangana, 2006. p. 73-87.

SILVA, L.; MENDONÇA, K. A violência escolar em matérias de jornal: um imaginário construído em Belém-PA. Comunicação \& Educação, São Paulo, v. 20, n. 1, p. 39-49, 2015. Disponível em: http://www.journals.usp.br/comueduc/article/view/80022. Acesso em: 22 mar. 2018.

STAKE, R. Pesquisa qualitativa/naturalista: problemas epistemológicos. Educação e seleção, n. 7, p. 19-27, 2013.

THIOLLENT, M.; COLETTE, M. Pesquisa-ação, universidade e sociedade. In: COLÓQUIO INTERNACIONAL SOBRE GESTÃO UNIVERSITÁRIA NAS AMÉRICAS, 23., 2013, Flórianopolis. Anais... Florianópolis: UFSC, 2013. Disponível em: https://repositorio.ufsc.br/handle/123456789/114882. Acesso em: 12 jun. 2018.

WEFFORT, F. Prefácio Educação e Política: reflexões sociológicas sobre uma pedagogia da Liberdade. In: FREIRE, P. Educaşão como prática da liberdade. 36. ed. rev. e atual. São Paulo: Paz e Terra, 2014. p. 1-26.

RECEBIDO: $29 / 11 / 2019$

APROVADO: $18 / 05 / 2020$

RECEIVED: $11 / 29 / 2019$

APPROVED: 05/18/2020

RECIBIDO: $29 / 11 / 2019$

APROBADO: $18 / 05 / 2020$ 